Institutions

Markets

Technologies

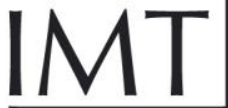

INSTITUTE

FOR ADVANCED

STUDIES

LUCCA

ISSN 2279-6894

IMT LUCCA EIC WORKING

PAPER SERIES 02

May 2012

\title{
Closing the gap? \\ Dynamic analyses of emission efficiency and sector productivity \\ in Europe
}

Giovanni Marin 
ISSN 2279-6894

IMT LUCCA EIC WORKING PAPER SERIES \#02/2012

(C) IMT-Institutions, Markets, Technologies, Institute for Advanced Studies, Lucca

Piazza San Ponziano 6, 55100 Lucca

Research Area

Economics and institutional change

\section{Closing the gap? Dynamic analyses of emission efficiency and sector productivity in Europe}

\section{Giovanni Marin}

IMT Institute for Advanced Studies Lucca 


\title{
Closing the gap? Dynamic analyses of emission efficiency and sector productivity in Europe*
}

\author{
Giovanni Marin ${ }^{\dagger}$
}

\begin{abstract}
This paper investigates the patterns of emission efficiency (value added per emission) growth of 23 manufacturing sectors in 12 European countries with a focus on five emissions ( $\mathrm{CO} 2$, NOx, NMVOC, $\mathrm{SOx}$ and $\mathrm{CO}$ ). Emission efficiency growth is expected to be triggered by improvements in the efficiency of frontier countries through the diffusion of better technologies to laggard countries. This effect is likely to differ according to the distance from the frontier country. Finally, the role of productivity patterns (Total Factor Productivity) and energy prices dynamics is assessed.

Results based on the European NAMEA (National Accounting Matrix including Environmental Accounts) further merged with sector accounts highlight significant spillovers from leaders in emission efficiency and a general tendency to converge for laggard countries and sectors (except for NMVOC emission efficiency). Energy prices weakly induce improvements in emission efficiency, with the effect being generally stronger for sectors and countries farther away from the emission efficiency frontier. Finally, total factor productivity (TFP) is strongly correlated with emission efficiency while the distance from TFP frontier significantly harms emission efficiency growth.
\end{abstract}

Keywords: convergence, environmental efficiency, NAMEA, technological diffusion

JEL: O33, Q55, Q56

\section{Introduction}

A key factor in the attainment of environmental sustainability is the improvement of environmental efficiency of production and consumption ac-

\footnotetext{
*The author thanks Massimiliano Mazzanti, Valeria Costantini, Francesca Lotti, Massimo Riccaboni and Carlo Cambini for very their very useful comments and suggestions. A preliminary version of the paper has been published as book chapter in 'The Dynamics of Economic and Environmental Efficiency' (Mazzanti and Costantini, eds), 2012, Springer. This paper is part of my PhD thesis. Usual disclaimer applies.

${ }^{\dagger}$ IMT Lucca Advanced Studies, Piazza San Ponziano, 6, 55100 Lucca (Italy). E-mail: giovanni.marin@imtlucca.it
} 
tivities. Environmental efficiency improvements at the aggregate (country) level are a combination of structural change, with a shift of production and consumption toward more environmentally friendly sectors and products, and improvements in environmental efficiency within sectors and product categories determined by technological change ${ }^{1}$. In this framework, technological change directed at reducing environmental pressures is characterized by a double externality problem, with improvements in environmental efficiency (reductions in negative externalities) not valued by the markets in absence of specific regulations and with the usual knowledge spillovers (positive externality) that reduce the incentives to innovate (Jaffe et al, 2005).

The correction of the double externality requires a combination of both environmental and innovation policies to stimulate the introduction and diffusion of more efficient technologies and products. During the last decades, European institutions promoted the convergence to a common EU-wide framework for environmental policies. Among other reasons, highly heterogeneous environmental policies across European countries may induce distortions to competition and strategic uses of environmental policies to favour domestic economic actors. Strategic use of environmental policies could have led to a 'race to the bottom' to the less stringent standard. Moreover, the achievement of environmental sustainability has been identified by the Lisbon Strategy in 2000 both as an objective per se and as a mean of transforming the EU into 'the most competitive and dynamic knowledge-based economy in the world ${ }^{2}$.

In order to reduce the burden of environmental regulations for producers and consumers and exploit the potential early-mover advantage in environmental technologies, international diffusion of environmental innovations and technologies should be favoured. A harmonized and stable regulatory framework favours more radical (environmental) innovations and the transition to more environmentally efficient production technologies through the adoption of environmental innovations. Lanjouw and Mody (1996) investigate the diffusion of environmental innovations using data on environmental patents and on trade flows in pollution control equipment. They emphasize the importance of both embodied (in pollution control equipment) and disembodied (through international patenting) diffusion of environmental innovations and the relevance of regulatory stringency as driver of diffusion. Popp (2006) investigates the extent to which the rate of patenting in pollution abatement technologies was triggered by the introduction of NOx and SO2 regulations in the US, Japan and Germany, the world's technological leaders. Environmental innovations in these countries respond to both domestic and foreign environmental regulations. An interesting result in Popp

\footnotetext{
${ }^{1}$ For an extensive review of the literature on the role of technological change in environmental issues, refer to Popp et al (2009).

${ }^{2}$ http://europa.eu/scadplus/glossary/lisbon_strategy_en.htm
} 
(2006) is the need for 'domestic' knowledge even when domestic regulations follow regulations and innovation efforts in other countries. Foreign environmental innovations introduced to reduce compliance costs in early regulator countries, once adopted by 'followers', are not enough and follower countries need to introduce complementary innovations.

Another channel through which environmental efficiency in the technological leader countries and the distance from the leader affect domestic environmental efficiency is related to the diffusion of environmental policies. Lovely and Popp (2011) use data on patented innovations for SO2 and NOx emissions abatement in coal-fired power plants to show the extent to which innovations in countries on the technological frontier induce the introduction of more stringent pollution control policies in other countries. Improvements in the abatement technology obtained in leader countries reduce the abatement costs in other countries thus favouring the diffusion of more stringent environmental standards.

The diffusion of technologies to improve environmental efficiency may also occur within a country through inter-sectoral flows of knowledge (Corradini et al, 2011). Knowledge flows may occur both by embodiment of more efficient environmental technologies in intermediate goods or capital goods and by pure 'immaterial' knowledge flows.

A final consideration relates to domestic drivers of emission efficiency. Environmental regulation is expected to be a crucial factor in spurring environmental efficiency, especially due to the (pure or impure) public good nature of environmental efficiency improvements. Even though different kinds of environmental regulation are characterized by heterogeneous levels of efficiency in meeting their environmental targets ${ }^{3}$, the effect of environmental policies is in the direction of improving environmental efficiency by definition ${ }^{4}$. Another important 'domestic' driver of emission efficiency is the domestic stock of knowledge in environmental technologies (Carrión-Flores and Innes, 2010). Domestic actors may strategically invest in environmental innovations to exploit early mover advantages in the world markets for environmental technologies. These strategies could be partly independent of the incentives to reduce compliance costs for domestic environmental policies (Porter and van der Linde, 1995). The 'side effects' of these innovation strategies may be an autonomous (from environmental policies) improve-

\footnotetext{
${ }^{3}$ Environmental regulations can be classified according to various criteria. The most common distinction is between command-and-control regulations, with no reward for overcompliance, and market-based regulations, according to which environmental externalities are priced. A second classification which is relevant in the context of this paper is related to the environmental scope of regulations, that is, the variety of environmental issues targeted by the regulation. Regulations with a wide scope are likely to reduce overall compliance costs for single policy instruments because they exploit the complementarities between the abatement of distinct environmental externalities in a more efficient way.

${ }^{4}$ Policies aimed at targeting specific environmental issues may, however, generate negative effects on other environmental issues.
} 
ment of domestic environmental efficiency and the tightening of domestic environmental policies as a consequence of reduced compliance costs. Environmental policies and environmental innovation strategies are generally targeted to very narrow environmental issues, which could limit their effects on specific economic sectors or to specific environmental problems. Moreover, market-based environmental policies such as environmental taxes and emission trading schemes are generally characterized by low values for external costs (taxes) and polluting rights (emission trading schemes), leading to weak inducement effects. This weak inducement has been substantially compensated by the dynamics of energy prices. Due to their pervasiveness (Costantini and Mazzanti, 2010), with effects on the whole supply chain and on consumers, energy prices have been identified as a crucial driver of energy efficiency (Newell et al, 1999; Popp, 2002), which is one of the most important components of emission efficiency strategies ${ }^{5}$. The channel through which energy prices are likely to improve energy (and thus emission) efficiency is the classical idea of Hicksian induced innovation, according to which an increase in the relative price of an input triggers innovation aimed at reducing the use (i.e. increasing the efficiency) of that input. Energy price shocks, such as oil shocks in 1973 and 1980, were sources of very significant structural changes in carbon dioxide emissions (Moomaw and Unruh, 1997; Mazzanti and Musolesi, 2010) while regulatory efforts such as the ratification of the Kyoto protocol did not generate significant breaks (Marin and Mazzanti (in press) for Italy). The pervasiveness of energy prices as a driver of emission efficiency also regards the great variety of air emissions affected by changes in energy prices and induced improvements in energy efficiency. On the one hand, high overall prices induce end-use improvements in energy efficiency, with a reduction (or a slow down) of energy production and beneficial effects on the abatement of all types of air emissions. On the other hand, shocks affecting the price of specific fuels will also induce changes in the energy mix, with differentiated effects on different types of emissions.

To sum up, this paper aims to find evidence for the following research questions:

- what are the drivers of sectoral emission efficiency growth in Europe?

- to what extent do improvements in emission efficiency in the technological frontier spread to laggard countries? What is the role of the emission efficiency gap?

- do energy prices dynamics affect emission efficiency growth? Does

\footnotetext{
${ }^{5}$ The link between energy efficiency and emission efficiency is very strict for CO2 emissions because, differently from other air pollutant, they cannot be easily abated by means of filters or, more generally, end-of-pipe equipment. Moreover, in addition to aggregate energy price indexes, the relative price of different fossil fuels is likely to substantially affect the environmental effect of energy price patterns due to changes in the fuel mix.
} 
this inducement change according to the distance from the emission efficiency frontier?

- do productivity (total factor productivity) growth and gap affect the pattern of emission efficiency?

- are there systematic differences between different types of emissions?

The paper is organized as follows. Section 2 discusses the empirical model used to investigate the drivers of sectoral emission efficiency, section 3 describes data sources, section 4 discusses the most relevant results and section 5 concludes.

\section{Model}

In order to investigate the drivers of emission efficiency improvements and the patterns of emission efficiency diffusion I use an adapted version of a quite standard empirical framework to account for productivity growth at the industry level. The general idea ${ }^{6}$ is that productivity level (total factor productivity - TFP - in early applications of the model) is an $\operatorname{ARDL}(1,1)^{7}$ process which is cointegrated with the level of TFP of the technological frontier. Under the assumption of long run homogeneity, TFP growth is described by the following equation:

$$
\begin{aligned}
& \triangle \log \left(\mathrm{TFP}_{c, s, t}\right)=\beta_{1} \triangle \log \left(\mathrm{TFP}_{F, s, t}\right)+ \\
& +\beta_{2}\left[\log \left(\mathrm{TFP}_{F, s, t-1}\right)-\log \left(\mathrm{TFP}_{c, s, t-1}\right)\right]+\epsilon_{c, s, t}
\end{aligned}
$$

Productivity growth in country $c$, sector $s$ and year $t$ is positively related to the growth in the technological frontier country $F$ and to the distance from the technological frontier. The rationale is that improvements in productivity in the most productive countries (technological frontier) enlarge the production possibility set (Nicoletti and Scarpetta, 2003) allowing laggard countries to improve their own productivity. Moreover, conditional on that effect, the distance from the technological frontier (technological gap) is expected to positively affect productivity growth. The idea is that the greater the distance from the frontier, the greater the marginal returns of adopting new technologies. A positive $\beta_{2}$ will result in a decreasing speed of convergence the closer a sector is to the frontier.

This basic model was employed in several OECD studies to investigate the effect of innovation, labour market institutions (Scarpetta and Tressel,

\footnotetext{
${ }^{6}$ I briefly describe the model used by Scarpetta and Tressel (2002), and Nicoletti and Scarpetta (2003).

${ }^{7}$ Auto regressive distributed lag of order 1.
} 
2002), product market competition and anticompetitive regulations (Nicoletti and Scarpetta, 2003) on productivity growth.

In the current paper I adapt this model to estimate improvements (if any) of sectoral emission efficiency. Emission efficiency growth (expressed in terms of value added per unit of emission) is a function of emission efficiency growth in the frontier country and of the gap in emission efficiency from the frontier country. Growth of emission efficiency 'at the frontier' is expected to induce improvements in all countries due to the (partial) international diffusion of new, more efficient technologies. Diffusion may take place through various channels: embodiment in capital goods, imitation or disembodied transfer (e.g. patent licensing).

Moreover, I expect overall (economic) production technology to play a role in emission efficiency growth. The idea is that a technology that improve 'economic' productivity (i.e. greater value added for the same amount of inputs) will also result in a (either intended or not) increase in 'environmental' efficiency. To account for this effect I add TFP growth (both in the country and in the frontier) and the technological gap in terms of TFP as covariates. I expect domestic TFP growth to positively positively emission efficiency. Both Mazzanti and Zoboli (2009) and Marin and Mazzanti (in press) consider the relationship between labour productivity and emission efficiency for Italian sectors, testing for non-linearities. Depending on the indicator for emission efficiency (emission per value added in Mazzanti and Zoboli (2009) and emission per labour unit in Marin and Mazzanti (in press) ${ }^{8}$ ), they find either weak (emission per labour) or moderate (emission per value added) complementarity between emission efficiency and labour productivity, with the magnitude being specific to both emission type and macro-sector. Cole et al (2005) use a more structured empirical model to assess the role of industrial characteristics and environmental regulation in determining the level of sectoral air pollution for the UK. Among other regressors, they consider the effect of total factor productivity on air emissions, finding a negative (increased emission efficiency) significant effect in most of the specifications. These results highlight the potential complementarities between economic (productivity) and environmental (efficiency) performance, at least at the sector level.

In addition to this direct effect, being distant from the technological leader could be an indication of general technological laggardness of the sector, with potential negative effects on both economic and environmental

\footnotetext{
${ }^{8}$ In a log-linear setting, it is possible to evaluate the relationship between estimates using emission per labour (E/L) and estimates using emission per value added (E/VA). The log-linear relationship between emission per value added and labour productivity (VA/L) is given by $\mathrm{E} / \mathrm{VA}=(\mathrm{VA} / \mathrm{L})^{\beta}$. By multiplying both sides by $\mathrm{VA} / \mathrm{L}$ and rearranging, the relationship becomes $\mathrm{E} / \mathrm{L}=(\mathrm{VA} / \mathrm{L})^{\beta+1}$, which means that, by construction, the coefficient in a log-linear setting using $\mathrm{E} / \mathrm{L}$ as emission efficiency indicator is exactly equal to the coefficient when using E/VA as emission efficiency indicator plus one.
} 
performance. Finally, TFP growth in the frontier country is included in order to account for the dynamics of the state of the technology of a sector.

To conclude, I investigate the effect of country-wide industry energy prices dynamics on emission efficiency. Following the approach of Scarpetta and Tressel (2002) and Nicoletti and Scarpetta (2003), whose focus is on product market regulations, I assume the inducement effect of energy prices on emission efficiency to change with the distance from the emission efficiency frontier. The idea is that very inefficient countries suffer more in terms of additional production costs than efficient countries because of a given increase in energy prices due to their greater energy (and thus emission) intensity of production. This potential higher costs is likely to amplify the inducement effect of energy prices on laggard countries.

The empirical model used here is described by the following equation:

$$
\begin{aligned}
& \triangle \log \left(\mathrm{VA}_{c, s, t} / \mathrm{E}_{c, s, t}\right)=\beta_{0}+\beta_{1} \triangle \log \left(\mathrm{VA}_{F, s, t} / \mathrm{E}_{F, s, t}\right)+ \\
& +\beta_{2} \text { gap_log }\left(\mathrm{VA}_{c, s, t-1} / \mathrm{E}_{c, s, t-1}\right)+\beta_{3} \triangle \log \left(\mathrm{TFP}_{c, s, t}\right)+ \\
& +\beta_{4} \triangle \log \left(\mathrm{TFP}_{F, s, t}\right)+\beta_{5} \text { gap_log }\left(\mathrm{TFP}_{c, s, t-1}\right)+ \\
& +\beta_{6} \triangle \text { ener_prices } \\
& c, t-1 \\
& +\beta_{7} \triangle \text { ener_prices }_{c, t-1} \times \text { gap_log }\left(\mathrm{VA}_{c, s, t-1} / \mathrm{E}_{c, s, t-1}\right)+ \\
& +\eta_{c}+\gamma_{s}+\delta_{t}+\epsilon_{c, s, t}
\end{aligned}
$$

where $\triangle \log \left(\mathrm{VA}_{c, s, t} / \mathrm{E}_{c, s, t}\right)$ represents the relative change in sectoral emission efficiency, $\triangle \log \left(\mathrm{VA}_{F, s, t} / \mathrm{E}_{F, s, t}\right)$ is the relative change in sectoral emission efficiency in the frontier country, gap_log $\left(\mathrm{VA}_{c, s, t-1} / \mathrm{E}_{c, s, t-1}\right)$ is the distance of sector $s$ in country $c$ from the emission efficiency frontier, $\triangle \log \left(\mathrm{TFP}_{c, s, t}\right)$

is TFP growth, $\triangle \log \left(\mathrm{TFP}_{F, s, t}\right)$ is TFP growth in the frontier country, gap_ $\log \left(\mathrm{TFP}_{c, s, t-1}\right)$ is the gap from the TFP frontier, $\triangle$ ener_prices $_{c, t-1}$ is the relative change in industrial energy prices and $\eta_{c}, \gamma_{s}$ and $\delta_{t}$ are, respectively, country, sector and year dummies.

All estimates have been performed using OLS regressions, with standard errors clustered by sector and country.

\section{Data}

I use sectoral data at the 2-digit NACE level covering 23 manufacturing sectors in 13 European countries (Austria, Belgium, Czech Republic, Germany, Denmark, Spain, Finland, France, Italy, the Netherlands, Norway, Sweden and the UK) over 12 years (1996-2007). The selection of countries is based on the availability of relevant data and by trying to include all large countries which are likely to be among the technological leaders of Europe. Some EU15 country have been excluded due to the very limited data coverage (Luxemburg, Portugal, Greece and Ireland). The choice to 
include Norway (which is not part of the European Union) is motivated by the fact that it is likely to belong to the group of technological leaders both in productivity and emissions efficiency and by the fact that Norway, through its membership of the European Environment Agency, partly shares the environmental regulatory framework of EU countries ${ }^{9}$. Moreover, the only country I included among those which joined the EU in 2004 is Czech Republic $^{10}$ because no other country had a satisfactory data coverage. A final consideration is needed concerning the focus on Europe only. Although many European countries are included in the group of technological leaders (both in terms of productivity and environmental efficiency), in many fields, the European technological frontier does not always coincide with the global technological frontier. In addition to Western European countries, the US, Canada, Japan, Australia and South Korea were found to be among the technological leaders (at least third in the ranking) by Scarpetta and Tressel (2002) based on TFP. The absence of these countries is likely to downward bias the relative gap from the frontier (either technological or for emission efficiency) and reduce the reliability of estimated improvements of the TFP and emission efficiency frontiers.

Data on value added, employment and gross fixed capital formation come from Eurostat and the OECD STAN (Structural Analysis) database. Missing values in the OECD STAN database were filled with data from EUROSTAT. Value added (in Euro) was deflated to 2000 prices according to country-specific deflators for manufacturing ${ }^{11}$. In the version of the results reported in the current paper, no PPP (Purchasing Power Parity) adjustment was performed ${ }^{12}$.

The capital stock variable, needed to obtain TFP estimates, was built by using the perpetual inventory method. Data on capital stock in OECD STAN has several missing values as well as the variable 'gross fixed capital formation' in constant prices. I use gross fixed capital formation (GFCF) in current prices, deflated with country-specific manufacturing deflators. The initial (1980, when available, or the first year of the series of sectoral gross fixed capital formation) fixed capital stock (K) for sector $s$ and country $c$

\footnotetext{
${ }^{9}$ Another potential technological leader in Europe not belonging to the EU27 is Switzerland. However, due to a very high proportion of missing observations in relevant variables, its inclusion in the sample was not possible.

${ }^{10}$ Results excluding Czech Republic do not change substantially from those reported in this paper.

${ }^{11}$ When using sector-specific deflators for value added and aggregate deflators for gross fixed capital formation, production function estimates are not plausible, with negative elasticity for capital.

${ }^{12}$ Estimates excluding Norway were performed using time-invariant PPP (sectorspecific or aggregate for manufacturing goods) adjustments obtained from EU KLEMS (www.euklems.eu). Results for the emission efficiency growth equation did not change substantially while the estimates of the labour and capital shares in the production function were quite unstable. However, sector-level PPP coupled with aggregate price deflators is likely to give rise to substantial measurement errors.
} 
was set to:

$$
\mathrm{K}_{c, s, 0}=\mathrm{GFCF}_{c, s, 0} /(\delta+g)
$$

where $g$ is the average growth rate (set to zero when negative) of GFCF in the first 5 years of the series and $\delta$ is the depreciation rate (set to 0.04). For $t>0$, the fixed capital stock was computed according to the following equation:

$$
\mathrm{K}_{c, s, t}=(1-\delta) \times \mathrm{K}_{c, s, t-1}+\mathrm{GFCF}_{c, s, t}
$$

Data on labour input refers to simple employees count (OECD STAN). This is an imperfect measure of labour input because there is no adjustment for full-time / part-time employees and for the actual number of hours worked. However, country coverage and reliability of employees count was much greater than measures of total hours worked or full-time equivalent estimates. Robustness checks were performed on a sub-sample with information on hours worked and full time equivalent estimates: no relevant difference was found ${ }^{13}$.

Data on sectoral air emission come from the Eurostat NAMEA (National Accounting Matrix including Environmental Accounts) database. By construction, environmental pressures reported in NAMEA are consistent with the full set of national economic accounts because they use the same definitions and classifications as national accounts. The main advantage of NAMEA relative to standard environmental statistics is the direct link between environmental externalities and economic aggregates, based on the residential principle (environmental pressures by resident units only) and on the consideration of anthropogenic sources only (emissions from natural sources such as volcanos are excluded). Moreover, the European NAMEA currently covers a remarkable variety of air emissions. Here I focus on air emissions of carbon dioxide (CO2), sulphur oxides ( $\mathrm{SOx}$ ), nitrogen oxides (NOx), non-methane volatile organic compounds (NMVOC) and carbon monoxide (CO). The main source of all emissions is the combustion of fossil fuels ${ }^{14}$. For additional information on the features of these emissions refer to Appendix A.

Finally, data on energy price come from IEA and they describe yearly relative changes in the price index of energy inputs for the industrial sector.

In order to obtain a rough estimate of the level of the production technology, I compute an approximate measure of total factor productivity (TFP henceforth). TFP has been estimated as the residual of a constant returns to

\footnotetext{
${ }^{13}$ Pairwise correlation among employees count, hours worked and full-time equivalent estimates is slightly above 99.5 percent.

${ }^{14}$ Other relevant sources of NMVOC emissions are paintings, solvents and coatings.
} 
Figure 1: Distribution of productivity and environmental efficiency relative gaps

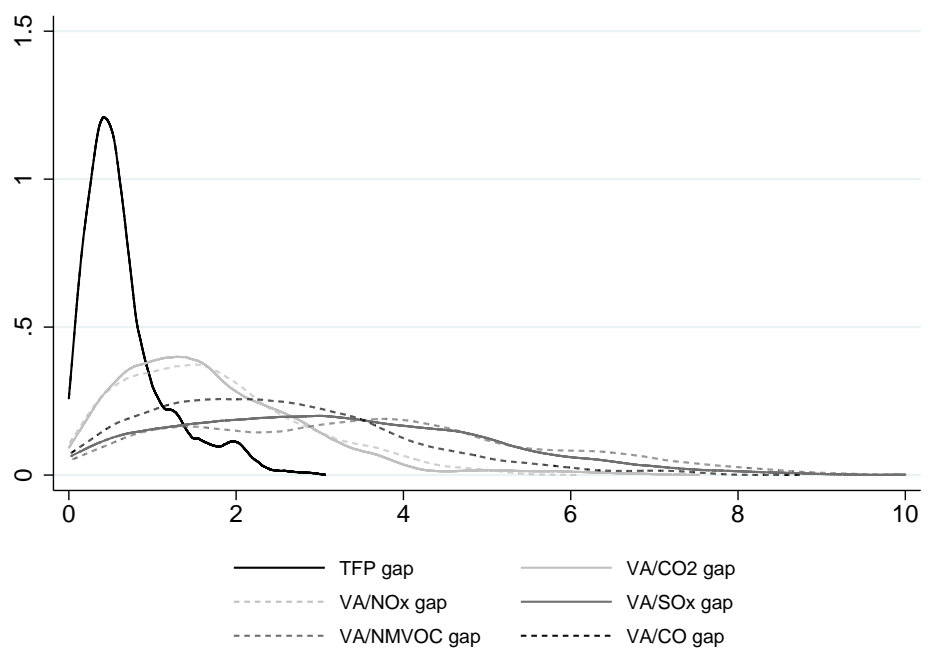

scale Cobb-Douglas production function, with value added as output measure and capital stock and labour (employees count) as inputs. The sum of the labour and capital coefficients was constrained to be 1 (constant returns to scale) and year and sector dummies were included in order to control for sector-specific technologies and Europe-wide shocks. The estimated labour share, corresponding to the elasticity of value added with respect to labour under the assumption of perfect competition, is 61.5 percent. Alternative measures of $\mathrm{TFP}^{15}$ were employed with very small changes in the results.

This data potentially relies 3588 observations. Despite ad hoc adjustment, some missing values remain ${ }^{16}$. Moreover, I excluded both outlier observations (labour productivity growth or reduction greater than 50 percent) and small sectors (the first percentile of sectors in terms of manufacturing value added or employment) to avoid potentially great measurement errors in sector representing a negligible share of an economy. Measurement errors may depend on the fact that a very small sector could include secondary activities only, with little or misleading information on the true state of the technology and on emission efficiency of the sector in a specific country.

Figure 1 shows the distribution of percentage gaps in both TFP and

\footnotetext{
${ }^{15}$ Alternative measures consisted in TFP estimated as the residual of a translog production function and a Cobb-Douglas with no CRS assumption. Moreover, estimates on smaller samples with value added and gross fixed capital formation deflated with sectorspecific deflators gave rise to very similar results in terms of labour share and TFP estimates.

${ }^{16}$ Spain for 1996, France for 1996-1999 (except sectors 20, 26 and 29, for a total of 80 missing values), Netherlands 1996-2001 (except sectors 20-29, for a total of 78 missing values) and other more scattered missing data.
} 
Table 1: Descriptive statistics

\begin{tabular}{lccccccc}
\hline Variable & Mean & 25th pct & Median & 75 th pct & Min & Max & Coeff var \\
\hline $\log$ (VA) & 21.39 & 20.37 & 21.39 & 22.54 & 16.18 & 25.11 & .07281 \\
$\log (\mathrm{K})$ & 22.36 & 21.26 & 22.43 & 23.53 & 16.96 & 26.33 & .07524 \\
$\log (\mathrm{L})$ & 10.5 & 9.62 & 10.49 & 11.64 & 5.298 & 13.93 & .147 \\
Trergy prices & .02744 & -.004866 & .02531 & .05842 & -.151 & .1593 & 1.917 \\
TFP & $8.57 \mathrm{e}-09$ & -.1415 & .06369 & .2662 & -2.041 & 1.652 & - \\
$\log$ (VA/L) & 10.89 & 10.69 & 10.93 & 11.19 & 8.191 & 13.16 & .05993 \\
$\log$ (VA/CO2) & 15.63 & 14.62 & 15.96 & 16.76 & 10.43 & 23.2 & .1109 \\
$\log$ (VA/NOx) & 14.61 & 13.52 & 14.75 & 15.72 & 9.943 & 20.75 & .1088 \\
$\log$ (VA/SOx) & 16.09 & 14.21 & 16.19 & 17.95 & 9.095 & 25.58 & .1642 \\
$\log$ (VA/NMVOC) & 14.74 & 13.17 & 14.39 & 16.21 & 7.653 & 23.32 & .1434 \\
$\log$ (VA/CO) & 14.46 & 13.57 & 14.65 & 15.58 & 8.322 & 22.3 & .1276 \\
TFP gap & .6159 & .264 & .4996 & .8006 & 0 & 3.106 & .8482 \\
$\log$ (VA/L) gap & .5434 & .1728 & .3646 & .6871 & 0 & 2.986 & 1.043 \\
$\log$ (VA/CO2) gap & 1.584 & .7163 & 1.412 & 2.251 & 0 & 7.359 & .7591 \\
$\log$ (VA/NOx) gap & 1.604 & .713 & 1.473 & 2.29 & 0 & 5.936 & .7184 \\
$\log$ (VA/SOx) gap & 2.9 & 1.358 & 2.779 & 4.267 & 0 & 10.52 & .6777 \\
$\log$ (VA/NMVOC) gap & 3.217 & 1.378 & 3.156 & 4.625 & 0 & 11.87 & .6849 \\
$\log$ (VA/CO) gap & 2.281 & 1.06 & 2.138 & 3.284 & 0 & 8.496 & .6969 \\
TFP frontier & .6159 & .4383 & .5547 & .7284 & .2201 & 2.071 & .4224 \\
$\log$ (VA/L) frontier & 11.44 & 11.1 & 11.34 & 11.66 & 10.64 & 13.16 & .04423 \\
$\log$ (VA/CO2) frontier & 17.21 & 16.06 & 17.38 & 18.39 & 12.4 & 23.2 & .1175 \\
$\log$ (VA/NOx) frontier & 16.21 & 14.92 & 16.41 & 17.3 & 12.1 & 20.75 & .1107 \\
$\log$ (VA/SOx) frontier & 18.99 & 17.31 & 19.13 & 20.68 & 10.79 & 25.58 & .1419 \\
$\log$ (VA/NMVOC) frontier & 17.96 & 16.72 & 17.76 & 18.94 & 12.5 & 23.32 & .1083 \\
$\log$ (VA/CO) frontier & 16.74 & 15.76 & 16.45 & 17.63 & 12.43 & 22.3 & .09733 \\
\hline
\end{tabular}

environmental efficiency (value added per unit of emissions). Interestingly, environmentally efficiency is much more dispersed than productivity with still great potentials for laggard countries and sectors to converge towards more environmentally efficient technologies. The lack of convergence depends on the 'external' nature of the benefits arising from environmental efficiency improvements as opposed to standard TFP improvements.

The gap is relatively small for $\mathrm{CO} 2$ and NOx emission efficiency while it is relevant for CO, SOx and NMVOC emission efficiency. This may seem a quite surprising result, given that local pollutants are regulated more strictly than $\mathrm{CO} 2$ emissions at European level, with potential greater homogeneity. However, pollutants are generally reduced with end-of-pipe technology which represent a pure cost for polluting firms while carbon dioxide emissions are very strongly correlated to energy use. The generally lower gap in CO2 efficiency could be the result of its strict correlation with energy use which is characterized by a substantial component of private benefit relative to pollutant emissions.

Descriptive statistics for relevant variables are reported in table 1.

\section{Results}

For all emissions, I report results for various versions of the baseline model, from the simplest version with no role for energy prices and TFP to the most complete version including energy prices and TFP. Results for the full sample of manufacturing sectors are reported in tables 2-6. A first remarkable result is the positive effect of emission efficiency improvements in the frontier country on domestic sectoral emission efficiency growth. This 
Table 2: Estimates for $\mathrm{CO} 2$ emission efficiency

\begin{tabular}{|c|c|c|c|c|c|c|}
\hline$\triangle \log (\mathrm{VA} / \mathrm{CO} 2)$ & (1) & (2) & (3) & (4) & (5) & (6) \\
\hline$\triangle \mathrm{VA} / \mathrm{CO} 2$ frontier & $\begin{array}{l}0.0319^{*} \\
(0.0192)\end{array}$ & $\begin{array}{c}0.0384^{* *} \\
(0.0189)\end{array}$ & $\begin{array}{c}0.0342^{*} \\
(0.0189)\end{array}$ & $\begin{array}{c}0.0407^{* *} \\
(0.0187)\end{array}$ & $\begin{array}{c}0.0379^{* *} \\
(0.0170)\end{array}$ & $\begin{array}{c}0.0404 * * \\
(0.0170)\end{array}$ \\
\hline $\mathrm{VA} / \mathrm{CO} 2$ gap $(\mathrm{t}-1)$ & $\begin{array}{c}0.00530 \\
(0.00515)\end{array}$ & $\begin{array}{c}0.0196 * * * \\
(0.00591)\end{array}$ & $\begin{array}{c}0.00160 \\
(0.00533)\end{array}$ & $\begin{array}{c}0.0152^{* * *} \\
(0.00589)\end{array}$ & $\begin{array}{c}0.0130 * * * \\
(0.00497)\end{array}$ & $\begin{array}{c}0.0184 * * * \\
(0.00537)\end{array}$ \\
\hline$\triangle$ energy prices & & & $\begin{array}{l}0.0522 \\
(0.144)\end{array}$ & $\begin{array}{l}0.0317 \\
(0.145)\end{array}$ & $\begin{array}{l}0.0611 \\
(0.132)\end{array}$ & $\begin{array}{l}0.0540 \\
(0.133)\end{array}$ \\
\hline$\triangle$ energy prices $x$ & & & $0.142^{*}$ & $0.152^{*}$ & 0.0913 & 0.110 \\
\hline $\mathrm{VA} / \mathrm{CO} 2 \operatorname{gap}(\mathrm{t}-1)$ & & & $(0.0791)$ & $(0.0781)$ & $(0.0718)$ & $(0.0715)$ \\
\hline$\triangle \mathrm{TFP}$ & & & & & $\begin{array}{c}0.981^{* * *} \\
(0.0396)\end{array}$ & $\begin{array}{c}0.960^{* * * *} \\
(0.0399)\end{array}$ \\
\hline$\triangle \mathrm{TFP}$ frontier & & & & & $\begin{array}{c}-0.0446^{*} \\
(0.0247)\end{array}$ & $\begin{array}{c}-0.0519^{* *} \\
(0.0248)\end{array}$ \\
\hline TFP gap (t-1) & & & & & $\begin{array}{c}-0.0431^{* * * *} \\
(0.00786)\end{array}$ & $\begin{array}{c}-0.0704^{* * * *} \\
(0.0152)\end{array}$ \\
\hline Constant & $\begin{array}{c}-0.0240 \\
(0.0213)\end{array}$ & $\begin{array}{c}-0.0493^{* *} \\
(0.0227)\end{array}$ & $\begin{array}{c}-0.0244 \\
(0.0219)\end{array}$ & $\begin{array}{c}-0.0494 * * \\
(0.0231)\end{array}$ & $\begin{array}{l}-0.0107 \\
(0.0212)\end{array}$ & $\begin{array}{l}-0.0314 \\
(0.0237)\end{array}$ \\
\hline $\mathrm{F}$ & $3.008^{* * *}$ & $5.970 * * *$ & $3.229 * * *$ & $5.874^{* * *}$ & $28.81 * * *$ & $26.02^{* * *}$ \\
\hline $\mathrm{R}$ squared & 0.0290 & 0.0703 & 0.0337 & 0.0751 & 0.268 & 0.288 \\
\hline Year dummies $(\mathrm{F})$ & $5.182^{* * *}$ & $5.338^{* * *}$ & $6.198^{* * *}$ & $6.365^{* * *}$ & $8.716^{* * *}$ & $8.891 * * *$ \\
\hline Sector dummies (F) & 0.780 & 0.851 & 0.762 & 0.833 & 0.996 & 1.136 \\
\hline Country dummies (F) & & $12.08^{* * *}$ & & $12.19^{* * *}$ & & $5.214^{* * *}$ \\
\hline Ramsey o.v. test (F) & 0.662 & $3.590^{* *}$ & 0.831 & $4.813^{* * *}$ & 0.469 & 1.657 \\
\hline $\mathrm{N}$ & 3115 & 3115 & 3115 & 3115 & 3115 & 3115 \\
\hline
\end{tabular}

result is robust in all specifications and for all emissions, its magnitude ranging from an elasticity of $0.03-0.04$ for $\mathrm{CO} 2$ emissions to an elasticity of 0.09-0.1 for SOx emissions. As expected, improvements in environmental efficiency at the frontier spill over to laggard countries with a beneficial effect on their emission efficiency growth. These positive spillovers may occur as a consequence of the diffusion of more environmental efficient technologies from 'frontier' countries and sectors to laggard countries and sectors.

The distance from the frontier country in terms of emission efficiency affects ${ }^{17}$ domestic emission efficiency growth positively and significantly for all emissions except NMVOC. This generally positive effect is a clear evidence of (beta) convergence in emission efficiency of laggard countries towards the emission efficiency frontier, with the speed of convergence being greater for countries and sectors with the biggest gap. It is evident from figure 1 that there are huge potentials of convergence in emission efficiency performance. However, it is clear that to accelerate the rate of convergence there is a need for further harmonization of environmental policies across countries and additional effort made to promote the diffusion of efficient technologies. The negative effect of the efficiency gap for NMVOC is small in magnitude and insignificant when including either country fixed effects or TFP growth (domestic and frontier country) and gap. Unlike other types of emission, NMVOC emission efficiency is not characterized by convergence patterns.

The coefficient for the change in energy prices $\left(\beta_{6}\right)$ describes the effect of prices on emission efficiency growth as if the sector was the technological leader whereas the actual effect of prices is given by $\beta_{6}+\beta_{7} \times$

\footnotetext{
${ }^{17}$ I refer here to the direct effect assuming no energy price change $\left(\triangle\right.$ ener_prices $_{c, t-1}=$ 0 ) in columns 3-6.
} 
Table 3: Estimates for NOx emission efficiency

\begin{tabular}{|c|c|c|c|c|c|c|}
\hline$\triangle \log (\mathrm{VA} / \mathrm{NO} \mathrm{x})$ & (1) & (2) & (3) & (4) & (5) & (6) \\
\hline$\triangle \mathrm{VA} / \mathrm{NOx}$ frontier & $\begin{array}{c}0.0562^{* * *} \\
(0.0202)\end{array}$ & $\begin{array}{c}0.0637^{* * *} * \\
(0.0203)\end{array}$ & $\begin{array}{c}0.0580^{* * *} \\
(0.0198)\end{array}$ & $\begin{array}{c}0.0654^{* * *} \\
(0.0200)\end{array}$ & $\begin{array}{c}0.0593^{* * *} * \\
(0.0186)\end{array}$ & $\begin{array}{c}0.0604 * * * \\
(0.0187)\end{array}$ \\
\hline VA/NOx gap (t-1) & $\begin{array}{c}0.0148^{* * * *} \\
(0.00476)\end{array}$ & $\begin{array}{c}0.0328^{* * *} * \\
(0.00667)\end{array}$ & $\begin{array}{l}0.0100 * * \\
(0.00492)\end{array}$ & $\begin{array}{c}0.0268^{* * *} * \\
(0.00653)\end{array}$ & $\begin{array}{c}0.0233^{* * *} * \\
(0.00507)\end{array}$ & $\begin{array}{c}0.0264^{* * *} \\
(0.00618)\end{array}$ \\
\hline$\triangle$ energy prices & & & $\begin{array}{c}0.156 \\
(0.187)\end{array}$ & $\begin{array}{c}0.113 \\
(0.189)\end{array}$ & $\begin{array}{c}0.133 \\
(0.180)\end{array}$ & $\begin{array}{c}0.124 \\
(0.184)\end{array}$ \\
\hline$\triangle$ energy prices $x$ & & & $0.185^{* *}$ & $0.202^{* *}$ & $0.146^{*}$ & $0.169^{* *}$ \\
\hline $\mathrm{VA} / \mathrm{NOx}(\mathrm{t}-1)$ gap & & & $(0.0864)$ & $(0.0848)$ & $(0.0806)$ & $(0.0803)$ \\
\hline$\triangle \mathrm{TFP}$ & & & & & $\begin{array}{l}1.016^{* * *} \\
(0.0438)\end{array}$ & $\begin{array}{c}0.991 * * * \\
(0.0436)\end{array}$ \\
\hline$\triangle T F P$ frontier & & & & & $\begin{array}{c}-0.0652^{* *} \\
(0.0319)\end{array}$ & $\begin{array}{c}-0.0665^{* *} * \\
(0.0327)\end{array}$ \\
\hline TFP gap (t-1) & & & & & $\begin{array}{c}-0.0522^{* * *} * \\
(0.00933)\end{array}$ & $\begin{array}{c}-0.0657^{* * *} * \\
(0.0162)\end{array}$ \\
\hline Constant & $\begin{array}{l}0.00508 \\
(0.0216)\end{array}$ & $\begin{array}{c}-0.0470^{* *} \\
(0.0232)\end{array}$ & $\begin{array}{c}0.00264 \\
(0.0232)\end{array}$ & $\begin{array}{c}-0.0484^{*} \\
(0.0247)\end{array}$ & $\begin{array}{c}0.0159 \\
(0.0229)\end{array}$ & $\begin{array}{l}-0.0342 \\
(0.0260)\end{array}$ \\
\hline $\mathrm{F}$ & $2.335 * * *$ & $5.782^{* * *}$ & $2.838^{* * *}$ & $5.850^{* * *}$ & $21.98^{* * *}$ & $22.65^{* * *}$ \\
\hline $\mathrm{R}$ squared & 0.0248 & 0.0630 & 0.0326 & 0.0704 & 0.210 & 0.230 \\
\hline Year dummies $(\mathrm{F})$ & $3.670^{* * *}$ & $3.786 * * *$ & $5.034^{* * *}$ & $5.154^{* * *}$ & $6.507^{* * *}$ & $6.536^{* * *}$ \\
\hline Sector dummies (F) & 0.982 & 1.275 & 0.954 & 1.247 & 0.691 & 0.746 \\
\hline Country dummies (F) & & $15.35^{* * *}$ & & $15.02 * * *$ & & $11.73^{* * *}$ \\
\hline Ramsey o.v. test (F) & $6.632^{* * *}$ & $3.234^{* *}$ & $3.986 * * *$ & $8.240 * * *$ & 0.178 & 0.227 \\
\hline $\mathrm{N}$ & 3115 & 3115 & 3115 & 3115 & 3115 & 3115 \\
\hline
\end{tabular}

gap_ $\log \left(\mathrm{VA}_{c, s, t-1} / \mathrm{E}_{c, s, t-1}\right)$. The effect on frontier sectors is always positive although it is significant for NMVOC and CO emissions only. The interaction term, on the other hand, is positive for CO2, NOx and SOx (weakly significant for $\mathrm{CO} 2$, significant for $\mathrm{NOx}$ and not significant for $\mathrm{SOx}$ ) and negative for NMVOC (though not significant) and CO (significant). A positive effect means that the effect of energy price changes on emission efficiency growth is increasing in the gap in emission efficiency from the frontier country, making laggards countries more sensitive to price changes than frontier countries. When computing marginal effects, the effect of energy prices for $\mathrm{CO} 2, \mathrm{NOx}$ and SOx increases with distance from the frontier. The overall effect of energy prices turns out to be positive and significant (10 percent of significnce already at the first quartile of emission efficiency gap). For these emissions, energy prices trigger significant improvement in laggard countries while the emission efficiency frontier is not significantly affected.

On the contrary, the marginal effect of energy prices decreases in the emission efficiency gap for NMVOC and CO emissions even though it is still strongly significant at the 90 percentile of the emission efficiency gap. In these cases, energy prices dynamics generates a stronger incentive for sectors that are close to the emission efficiency frontier than for laggard sectors. A possible explanation for the opposite results relative to $\mathrm{CO} 2$, NOx and $\mathrm{SOx}$ regarding the effect of energy prices may be related to opposite patterns of environmental technological change for laggards and frontier sectors. On the one hand, laggard sectors seem to focus on the improvement of energy efficiency (strongly correlated with $\mathrm{CO} 2$ efficiency) and on the abatement of more 'classical' pollutants such as SOx and NOx. On the other hand, sectors lying close to the emission efficiency frontier seem to be characterized 
Table 4: Estimates for NMVOC emission efficiency

\begin{tabular}{|c|c|c|c|c|c|c|}
\hline$\triangle \log (\mathrm{VA} / \mathrm{NMVOC})$ & (1) & (2) & (3) & (4) & (5) & (6) \\
\hline$\triangle \mathrm{VA} / \mathrm{NMVOC}$ frontier & $\begin{array}{l}0.0421^{*} \\
(0.0240)\end{array}$ & $\begin{array}{c}0.0484 * * \\
(0.0243)\end{array}$ & $\begin{array}{l}0.0416^{*} \\
(0.0237)\end{array}$ & $\begin{array}{c}0.0474^{* *} \\
(0.0239)\end{array}$ & $\begin{array}{l}0.0425^{*} \\
(0.0234)\end{array}$ & $\begin{array}{c}0.0468^{* *} \\
(0.0236)\end{array}$ \\
\hline VA/NMVOC gap (t-1) & $\begin{array}{c}-0.0122^{* * * *} \\
(0.00353)\end{array}$ & $\begin{array}{c}0.00156 \\
(0.00451)\end{array}$ & $\begin{array}{c}-0.00803^{* *} * \\
(0.00343)\end{array}$ & $\begin{array}{c}0.00424 \\
(0.00496)\end{array}$ & $\begin{array}{l}-0.00281 \\
(0.00351)\end{array}$ & $\begin{array}{c}0.00503 \\
(0.00488)\end{array}$ \\
\hline$\triangle$ energy prices & & & $\begin{array}{c}1.105^{* *} \\
(0.446)\end{array}$ & $\begin{array}{c}1.099^{* *} \\
(0.455)\end{array}$ & $\begin{array}{c}1.073^{* *} \\
(0.441)\end{array}$ & $\begin{array}{l}1.054^{* *} \\
(0.453)\end{array}$ \\
\hline$\triangle$ energy prices $x$ & & & -0.123 & -0.115 & -0.125 & -0.113 \\
\hline VA/NMVOC gap (t-1) & & & $(0.0828)$ & $(0.0825)$ & $(0.0819)$ & $(0.0822)$ \\
\hline$\triangle$ TFP & & & & & $\begin{array}{c}0.939^{* * *} \\
(0.0568)\end{array}$ & $\begin{array}{c}0.908 * * * \\
(0.0584)\end{array}$ \\
\hline$\triangle \mathrm{TFP}$ frontier & & & & & $\begin{array}{l}-0.0523 \\
(0.0385)\end{array}$ & $\begin{array}{c}-0.0518 \\
(0.0382)\end{array}$ \\
\hline TFP gap (t-1) & & & & & $\begin{array}{c}-0.0319 * * * \\
(0.0109)\end{array}$ & $\begin{array}{c}-0.0532^{* *} * \\
(0.0210)\end{array}$ \\
\hline Constant & $\begin{array}{c}0.0549 * * \\
(0.0246)\end{array}$ & $\begin{array}{l}-0.0119 \\
(0.0265)\end{array}$ & $\begin{array}{c}0.0181 \\
(0.0295)\end{array}$ & $\begin{array}{l}-0.0452 \\
(0.0330)\end{array}$ & $\begin{array}{c}0.0287 \\
(0.0285)\end{array}$ & $\begin{array}{l}-0.0335 \\
(0.0321)\end{array}$ \\
\hline $\mathrm{F}$ & $3.261^{* * *}$ & $4.919^{* * *}$ & $3.196^{* * *}$ & $4.754^{* * *}$ & $14.81 * * *$ & $16.03 * * *$ \\
\hline R squared & 0.0373 & 0.0676 & 0.0479 & 0.0777 & 0.139 & 0.159 \\
\hline Year dummies $(\mathrm{F})$ & $2.119^{* *}$ & $2.035^{* *}$ & $2.967^{* * *}$ & $2.928^{* * *}$ & $3.289^{* * *} *$ & $3.246^{* * *}$ \\
\hline Sector dummies $(\mathrm{F})$ & $3.155^{* * *}$ & $2.098^{* * *}$ & $3.032^{* * *}$ & $2.112^{* * *}$ & $3.462^{* * *}$ & $2.778^{* * *}$ \\
\hline Country dummies (F) & & $7.374^{* * *}$ & & $7.223^{* * *}$ & & $6.438 * * *$ \\
\hline Ramsey o.v. test (F) & $15.64^{* * *}$ & $172.9^{* * *}$ & $148.9^{* * *}$ & $253.8^{* * *}$ & $35.27^{* * *}$ & $93.40^{* * *}$ \\
\hline $\mathrm{N}$ & 3115 & 3115 & 3115 & 3115 & 3115 & 3115 \\
\hline
\end{tabular}

by fewer energy inefficiencies (and, consequently, higher marginal costs to improve energy efficiency) and by higher marginal costs for the abatement of classical pollutants due to the long tradition of stringent environmental standards.

The inclusion of productivity measures (total factor productivity TFP growth in the sector and in the frontier country and TFP gap from the frontier) in the last two columns does not affect substantially the estimates of other parameters. However, considering TFP has the consequence of improving substantially the goodness of fit ( $\mathrm{R}$ squared $)^{18}$. As expected, the relationship between sectoral TFP growth and emission efficiency growth is positive and strongly significant, with coefficients varying from a minimum of 0.86 (SOx without country fixed effects) to 1.04 (CO without country fixed effects). This means that an increase in TFP translates into a very similar increase in emission efficiency conditional on other covariates. This very robust result highlights the strong complementarity between economic productivity and environmental efficiency. The effect of TFP growth in the frontier country has a generally negative effect on emission efficiency growth, with the coefficient being statistically significant just for CO2 (5 percent), NOx (5 percent) and CO (10 percent only when including country fixed effects, insignificant otherwise). The insignificant or negative effect of TFP growth in the frontier country may suggest that frontier technological change is not explicitly directed to improve emission efficiency and, in some cases, there is a weak evidence of 'emission-intensive' technical change. Finally, the gap in TFP from the frontier country negatively and significantly

\footnotetext{
${ }^{18}$ No relevant improvements in the $\mathrm{R}$ squared is found for SOx estimates where the gain is of about 2-3 percent of explained variance.
} 
Table 5: Estimates for SOx emission efficiency

\begin{tabular}{|c|c|c|c|c|c|c|}
\hline$\triangle \log (\mathrm{VA} / \mathrm{SOx})$ & (1) & (2) & (3) & (4) & (5) & (6) \\
\hline$\triangle \mathrm{VA} / \mathrm{SOx}$ frontier & $\begin{array}{c}0.0901^{* * * *} \\
(0.0229)\end{array}$ & $\begin{array}{c}0.0965 * * * \\
(0.0232)\end{array}$ & $\begin{array}{c}0.0902^{* * * *} \\
(0.0228)\end{array}$ & $\begin{array}{c}0.0963^{* * *} \\
(0.0231)\end{array}$ & $\begin{array}{c}0.0926^{* * *} * \\
(0.0229)\end{array}$ & $\begin{array}{c}0.0979^{* * *} \\
(0.0230)\end{array}$ \\
\hline $\mathrm{VA} / \mathrm{SOx} \operatorname{gap}(\mathrm{t}-1)$ & $\begin{array}{c}0.0467 * * * \\
(0.00740)\end{array}$ & $\begin{array}{c}0.0605 * * * \\
(0.00882)\end{array}$ & $\begin{array}{c}0.0452^{* * *} \\
(0.00785)\end{array}$ & $\begin{array}{c}0.0582^{* * *} \\
(0.00912)\end{array}$ & $\begin{array}{c}0.0521 * * * \\
(0.00894)\end{array}$ & $\begin{array}{c}0.0608 * * * \\
(0.00935)\end{array}$ \\
\hline$\triangle$ energy prices & & & $\begin{array}{c}0.475 \\
(0.365)\end{array}$ & $\begin{array}{c}0.380 \\
(0.362)\end{array}$ & $\begin{array}{c}0.398 \\
(0.363)\end{array}$ & $\begin{array}{c}0.282 \\
(0.360)\end{array}$ \\
\hline$\triangle$ energy prices $X$ & & & 0.0753 & 0.0864 & 0.0684 & 0.105 \\
\hline $\mathrm{VA} / \mathrm{SO}$ gap $(\mathrm{t}-1)$ & & & $(0.0949)$ & $(0.0944)$ & $(0.0947)$ & $(0.0932)$ \\
\hline$\triangle \mathrm{TFP}$ & & & & & $\begin{array}{c}0.861 * * * \\
(0.0917)\end{array}$ & $\begin{array}{c}0.907^{* * *} * \\
(0.0969)\end{array}$ \\
\hline$\triangle \mathrm{TFP}$ frontier & & & & & $\begin{array}{c}0.000683 \\
(0.0759)\end{array}$ & $\begin{array}{c}-0.0368 \\
(0.0752)\end{array}$ \\
\hline TFP gap (t-1) & & & & & $\begin{array}{c}-0.0697^{* * *} * \\
(0.0247)\end{array}$ & $\begin{array}{c}-0.151 * * * \\
(0.0451)\end{array}$ \\
\hline Constant & $\begin{array}{c}0.0380 \\
(0.0371)\end{array}$ & $\begin{array}{c}-0.00240 \\
(0.0472)\end{array}$ & $\begin{array}{c}0.0251 \\
(0.0393)\end{array}$ & $\begin{array}{c}-0.0118 \\
(0.0471)\end{array}$ & $\begin{array}{c}0.0552 \\
(0.0393)\end{array}$ & $\begin{array}{c}0.0485 \\
(0.0496)\end{array}$ \\
\hline $\mathrm{F}$ & $4.888^{* * *}$ & $5.329^{* * *}$ & $4.926^{* * *}$ & $5.316^{* * *}$ & $7.387^{* * *}$ & $7.263^{* * *}$ \\
\hline $\mathrm{R}$ squared & 0.0580 & 0.0660 & 0.0610 & 0.0684 & 0.0882 & 0.0981 \\
\hline Year dummies (F) & $7.833^{* * *}$ & $7.928^{* * *}$ & $8.220^{* * *}$ & $8.342^{* * *}$ & $8.384^{* * *}$ & $8.028^{* * *}$ \\
\hline Sector dummies $(F)$ & $2.778^{* * *}$ & $3.087^{* * *}$ & $2.758^{* * *}$ & $3.045^{* * *}$ & $3.354^{* * *}$ & $3.862^{* * *}$ \\
\hline Country dummies (F) & & $2.716^{* * *}$ & & $2.458^{* * *}$ & & $2.644^{* * *}$ \\
\hline Ramsey o.v. test (F) & $47.20^{* * *}$ & $48.42^{* * *}$ & $47.88^{* * *}$ & $49.15^{* * *}$ & $11.55^{* * *}$ & $9.017^{* * *}$ \\
\hline $\mathrm{N}$ & 3115 & 3115 & 3115 & 3115 & 3115 & 3115 \\
\hline
\end{tabular}

affects emission efficiency growth in all cases. The existence of a negative effect of TFP gap further stresses the complementarity links between economic and environmental performance, especially since differences in emission efficiency were already accounted for. As stated in the previous section, results employing alternative measures of TFP or using labour productivity give rise to qualitatively very similar estimates.

Some considerations on year, sector and country fixed effects are needed. Year and country dummies are jointly strongly significant in all specifications and for all emissions. Significant Europe-wide time dummies possibly highlight the relevance of regulatory efforts at the European level affecting all countries.

Sector dummies, on the contrary, are not jointly significant for both for $\mathrm{CO} 2$ and NOx estimates, highlighting quite uniform efficiency patterns among sectors within countries for these types of emissions. On the contrary, they are jointly strongly significant for SOx, NMVOC and CO, highlighting heterogeneous patterns of emission efficiency potentially driven by sectorspecific environmental regulations.

Country dummies are jointly strongly significant in all cases, stressing the great heterogeneity of environmental efficiency and highlighting the relevance of systematic differences among countries in emission efficiency dynamics even after controlling for the gap in environmental efficiency and productivity.

Results reported in the paper do not change substantially when performing some simple robustness checks. The inclusion of outliers or small sectors does not influence either the magnitude or the significance of estimated coefficients. The use of more aggregate sector information, for example at 
Table 6: Estimates for CO emission efficiency

\begin{tabular}{|c|c|c|c|c|c|c|}
\hline$\triangle \log (\mathrm{VA} / \mathrm{CO})$ & (1) & (2) & (3) & (4) & (5) & (6) \\
\hline$\triangle \mathrm{VA} / \mathrm{CO}$ frontier & $\begin{array}{c}0.0758^{* * *} \\
(0.0258)\end{array}$ & $\begin{array}{c}0.0789^{* * *} \\
(0.0259)\end{array}$ & $\begin{array}{c}0.0734^{* * *} \\
(0.0251)\end{array}$ & $\begin{array}{c}0.0769^{* * *} \\
(0.0253)\end{array}$ & $\begin{array}{c}0.0760^{* * *} \\
(0.0245)\end{array}$ & $\begin{array}{c}0.0771 * * * \\
(0.0247)\end{array}$ \\
\hline $\mathrm{VA} / \mathrm{CO}$ gap $(\mathrm{t}-1)$ & $\begin{array}{c}0.0152^{* * *} \\
(0.00476)\end{array}$ & $\begin{array}{c}0.0240 * * * \\
(0.00622)\end{array}$ & $\begin{array}{l}0.0194^{* * *} * \\
(0.00505)\end{array}$ & $\begin{array}{c}0.0280^{* * *} * \\
(0.00666)\end{array}$ & $\begin{array}{l}0.0257^{* * *} \\
(0.00534)\end{array}$ & $\begin{array}{c}0.0276^{* * *} * \\
(0.00646)\end{array}$ \\
\hline$\triangle$ energy prices & & & $\begin{array}{c}1.438^{* * *} \\
(0.406)\end{array}$ & $\begin{array}{c}1.335^{* * *} \\
(0.393)\end{array}$ & $\begin{array}{c}1.450^{* * *} \\
(0.398)\end{array}$ & $\begin{array}{c}1.381^{* * *} \\
(0.392)\end{array}$ \\
\hline$\triangle$ energy prices $x$ & & & $-0.225^{* *}$ & $-0.196^{*}$ & $-0.273^{* *}$ & $-0.237^{* *}$ \\
\hline $\begin{array}{l}\text { VA /CO gap (t-1) } \\
\triangle \text { TFP }\end{array}$ & & & $(0.107)$ & $(0.102)$ & $\begin{array}{c}(0.107) \\
1.042^{* * *} \\
(0.0753)\end{array}$ & $\begin{array}{c}(0.102) \\
1.013^{* * *} \\
(0.0768)\end{array}$ \\
\hline$\triangle \mathrm{TFP}$ frontier & & & & & $\begin{array}{l}-0.0688 \\
(0.0428)\end{array}$ & $\begin{array}{c}-0.0720^{*} \\
(0.0431)\end{array}$ \\
\hline TFP gap (t-1) & & & & & $\begin{array}{c}-0.0575^{* * *} * \\
(0.0129)\end{array}$ & $\begin{array}{c}-0.0789 * * * \\
(0.0251)\end{array}$ \\
\hline Constant & $\begin{array}{c}0.0191 \\
(0.0314)\end{array}$ & $\begin{array}{c}-0.00121 \\
(0.0340)\end{array}$ & $\begin{array}{c}-0.0255 \\
(0.0355)\end{array}$ & $\begin{array}{c}-0.0425 \\
(0.0386)\end{array}$ & $\begin{array}{l}-0.00601 \\
(0.0343)\end{array}$ & $\begin{array}{l}-0.0236 \\
(0.0381)\end{array}$ \\
\hline $\mathrm{F}$ & $2.541 * * *$ & $6.218^{* * *}$ & $2.626^{* * *}$ & $5.936^{* * *}$ & $10.71 * * *$ & $13.99^{* * *}$ \\
\hline R squared & 0.0380 & 0.0756 & 0.0533 & 0.0883 & 0.143 & 0.168 \\
\hline Year dummies (F) & $1.685^{*}$ & $1.733^{*}$ & $2.889^{* * *}$ & $2.832 * * *$ & $3.445^{* * *}$ & $3.113^{* * *}$ \\
\hline Sector dummies $(\mathrm{F})$ & $2.418^{* * *}$ & $2.415^{* * *}$ & $2.419 * * *$ & $2.414^{* * *}$ & $2.367 * * *$ & $2.150 * * *$ \\
\hline Country dummies (F) & & $16.21^{* * *}$ & & $14.58^{* * *}$ & & $11.39 * * *$ \\
\hline Ramsey o.v. test $(\mathrm{F})$ & $3.265^{* *}$ & $96.58^{* * *}$ & $47.25 * * *$ & $166.7^{* * *}$ & $53.05 * * *$ & $116.5^{* * *}$ \\
\hline $\mathrm{N}$ & 3115 & 3115 & 3115 & 3115 & 3115 & 3115 \\
\hline
\end{tabular}

the level of subsection NACE with 14 manufacturing sectors, reduces the significance of many coefficients but the magnitude does not change ${ }^{19}$.

When removing specific countries or sectors (one by one) the magnitude of estimated coefficients does not change substantially even if significance is generally lower. Finally, tests on the presence of structural breaks in estimated coefficients were performed ${ }^{20}$. No significant structural break was found for CO2 and NMVOC emissions. Statistically significant breaks were found for NOx (1998 and 2000), SOx (2005) and CO (1999, 2001, 2002 and 2005) even though just three of them were significant at the 1 percent level (NOx 2000, SOx 2005 and CO 1999).

Tables 7-10 report estimates for sub-samples of sectors: sectors covered by the ETS ${ }^{21}$ (Emission Trading System for carbon dioxide emissions, introduced in 2005) or not, medium-high technology and medium-low technology

\footnotetext{
${ }^{19}$ The level of aggregation of sectoral data is always a relevant issues when dealing with indicators of environmental efficiency. An improvement in emission efficiency could simply be the result of the changing composition of sectors within the considered macro-sector (e.g. 2-digit) towards more emission efficient sub-sectors (e.g. 4-digit). The observed improvement may thus occur even in absence of any change in the production or abatement technology of the sectors. The reader should always consider this caveat when interpreting the results.

${ }^{20}$ I performed a Chow test by interacting a dummy variable identifying a specific time period with all covariates in the model described by equation 2 . The test (a simple $\mathrm{F}$ test) is performed by assuming, under the null hypothesis, that the parameters of all interaction terms are jointly equal to zero, thus indicating no structural break.

${ }^{21}$ The European ETS for carbon dioxide emissions covers plants operating in the following 2-digit NACE Rev 1.1 sectors: 21 (pulp, paper and paper products), 23 (coke, refined petroleum products and nuclear fuel), 26 (other non-metallic mineral products), 27 (basic metals) and 28 (fabricated metal products, except machinery and equipment).
} 
Table 7: Estimates for ETS sectors

\begin{tabular}{|c|c|c|c|c|c|}
\hline & $\mathrm{CO} 2$ & NOx & NMVOC & SOx & $\mathrm{CO}$ \\
\hline$\triangle \mathrm{VA} / \mathrm{E}$ frontier & $\begin{array}{l}0.0473^{*} \\
(0.0284)\end{array}$ & $\begin{array}{c}0.0841^{* * *} \\
(0.0294)\end{array}$ & $\begin{array}{c}0.0696 \\
(0.0484)\end{array}$ & $\begin{array}{l}0.0989^{*} \\
(0.0550)\end{array}$ & $\begin{array}{l}0.0716^{*} \\
(0.0428)\end{array}$ \\
\hline $\mathrm{VA} / \mathrm{E} \operatorname{gap}(\mathrm{t}-1)$ & $\begin{array}{c}0.00557 \\
(0.00684)\end{array}$ & $\begin{array}{c}0.00738 \\
(0.00804)\end{array}$ & $\begin{array}{l}-0.00358 \\
(0.00678)\end{array}$ & $\begin{array}{c}0.0444 \\
(0.0309)\end{array}$ & $\begin{array}{r}-0.000285 \\
(0.00927)\end{array}$ \\
\hline$\triangle$ energy prices & $\begin{array}{l}-0.247 \\
(0.186)\end{array}$ & $\begin{array}{l}-0.249 \\
(0.306)\end{array}$ & $\begin{array}{l}-0.462 \\
(0.854)\end{array}$ & $\begin{array}{c}0.892 \\
(0.738)\end{array}$ & $\begin{array}{c}0.565 \\
(0.910)\end{array}$ \\
\hline $\begin{array}{l}\triangle \text { energy prices } \times \\
\text { VA } / E \text { gap }(t-1)\end{array}$ & $\begin{array}{c}0.101 \\
(0.0979)\end{array}$ & $\begin{array}{l}0.240^{*} \\
(0.145)\end{array}$ & $\begin{array}{c}0.142 \\
(0.181)\end{array}$ & $\begin{array}{l}-0.191 \\
(0.191)\end{array}$ & $\begin{array}{r}-0.0765 \\
(0.207)\end{array}$ \\
\hline$\triangle \mathrm{TFP}$ & $\begin{array}{c}0.924^{* * *} \\
(0.0329)\end{array}$ & $\begin{array}{l}1.016^{* * *} * \\
(0.0488)\end{array}$ & $\begin{array}{l}1.025^{* * *} \\
(0.0831)\end{array}$ & $\begin{array}{c}0.854^{* * *} \\
(0.101)\end{array}$ & $\begin{array}{c}0.873^{* * *} * \\
(0.108)\end{array}$ \\
\hline$\triangle$ Frontier TFP & $\begin{array}{l}-0.0133 \\
(0.0370)\end{array}$ & $\begin{array}{l}-0.0317 \\
(0.0541)\end{array}$ & $\begin{array}{r}-0.0346 \\
(0.106)\end{array}$ & $\begin{array}{r}-0.0352 \\
(0.117)\end{array}$ & $\begin{array}{l}0.0834 \\
(0.122)\end{array}$ \\
\hline TFP gap (t-1) & $\begin{array}{l}-0.0149 \\
(0.0130)\end{array}$ & $\begin{array}{r}-0.00692 \\
(0.0186)\end{array}$ & $\begin{array}{c}-0.000658 \\
(0.0316)\end{array}$ & $\begin{array}{l}-0.0383 \\
(0.0477)\end{array}$ & $\begin{array}{c}0.0337 \\
(0.0418)\end{array}$ \\
\hline Constant & $\begin{array}{c}-0.0294 \\
(0.0199)\end{array}$ & $\begin{array}{l}-0.0171 \\
(0.0285)\end{array}$ & $\begin{array}{c}0.0439 \\
(0.0418)\end{array}$ & $\begin{array}{c}-0.0645 \\
(0.103)\end{array}$ & $\begin{array}{l}0.00252 \\
(0.0552)\end{array}$ \\
\hline $\mathrm{F}$ & $37.22 * * *$ & $26.86^{* * *}$ & $12.97 * * *$ & $8.352^{* * *}$ & $5.820 * * *$ \\
\hline $\mathrm{R}$ squared & 0.589 & 0.450 & 0.249 & 0.153 & 0.166 \\
\hline Year dummies $(\mathrm{F})$ & $2.672^{* * *}$ & $1.997^{* *}$ & 1.325 & $2.428 * * *$ & 0.734 \\
\hline Sector dummies (F) & 0.575 & 0.734 & 1.907 & $4.155^{* * *}$ & $4.112^{* * *}$ \\
\hline Country dummies (F) & $2.047^{* *}$ & $2.760^{* * *}$ & $2.466^{* * *}$ & $1.558^{*}$ & 1.519 \\
\hline Ramesey o.v. test (F) & 1.175 & 1.144 & 0.504 & $8.084^{* * *}$ & $3.851^{* * *}$ \\
\hline $\mathrm{N}$ & 712 & 712 & 712 & 712 & 712 \\
\hline
\end{tabular}

sectors $^{22}$. Results for ETS sectors (table 7) tend to be quite volatile, with very low significance for most covariates except TFP growth. The reduced significance may depend on the small size of the sample (less than one fourth of the full sample). Comparing the magnitude of estimated coefficients with baseline estimates, the effect of emission efficiency growth at the frontier is similar to the full sample while the gap in terms of emission efficiency has a systematically lower effect, with very small and always insignificant coefficients. This results underlines a weak tendency to converge of ETS sectors. With the only exception of SOx estimates, the effect of energy prices (both direct and conditional on the emission efficiency gap) is much lower than the effect for the full sample. This weak responsiveness to price signals is very relevant in the choice of an effective and efficient policy tool to limit air emissions. A cap and trade system such as the European ETS seems more appropriate than a tax on emissions to effectively reduce air emissions of these sectors. By setting quantitative aggregate targets, cap and trade systems ensure the effectiveness of the policy leaving some uncertainty on the overall cost of compliance. On the contrary, non-ETS sectors (table 8) are characterized by more robust results. Sectors characterized with a relevant gap from the emission efficiency frontier grow significantly faster for all emissions while being far from the productivity frontier affects negatively and significantly emission efficiency growth. Moreover, non-ETS sectors tend to be more responsive to energy prices than ETS sectors.

\footnotetext{
${ }^{22}$ According to the OECD, medium-high technology manufacturing sectors include the following 2-digit NACE Rev 1.1 sectors: 24 (chemicals and chemical products), 29 (machinery and equipment n.e.c.), 30-33 (electrical and optical equipment) and 34-35 (transport equipment) while the remaining manufacturing sectors are considered as medium-low technology sectors.
} 
Table 8: Estimates for non-ETS sectors

\begin{tabular}{|c|c|c|c|c|c|}
\hline & $\mathrm{CO} 2$ & $\mathrm{NOx}$ & NMVOC & $\mathrm{SOx}$ & $\mathrm{CO}$ \\
\hline$\triangle \mathrm{VA} / \mathrm{E}$ frontier & $\begin{array}{c}0.0421 * * \\
(0.0177)\end{array}$ & $\begin{array}{c}0.0614^{* * *} \\
(0.0199)\end{array}$ & $\begin{array}{l}0.0396 \\
(0.0254)\end{array}$ & $\begin{array}{c}0.0932^{* * *} \\
(0.0252)\end{array}$ & $\begin{array}{c}0.0795^{* * *} \\
(0.0281)\end{array}$ \\
\hline VA/E gap (t-1) & $\begin{array}{c}0.0250^{* * *} \\
(0.00669)\end{array}$ & $\begin{array}{c}0.0351^{* * *} \\
(0.00819)\end{array}$ & $\begin{array}{c}0.00827 \\
(0.00613)\end{array}$ & $\begin{array}{c}0.0646^{* * *} \\
(0.0100)\end{array}$ & $\begin{array}{r}0.0396 * * * \\
(0.00856)\end{array}$ \\
\hline$\triangle$ energy prices & $\begin{array}{l}0.152 \\
(0.164)\end{array}$ & $\begin{array}{l}0.223 \\
(0.226)\end{array}$ & $\begin{array}{c}1.603^{* * *} \\
(0.525)\end{array}$ & $\begin{array}{c}0.119 \\
(0.429)\end{array}$ & $\begin{array}{c}1.561^{* * *} \\
(0.437)\end{array}$ \\
\hline $\begin{array}{l}\triangle \text { energy prices } \times \\
\text { VA } / \mathrm{E} \text { gap }(\mathrm{t}-1)\end{array}$ & $\begin{array}{c}0.102 \\
(0.0838)\end{array}$ & $\begin{array}{l}0.155^{*} \\
(0.0928)\end{array}$ & $\begin{array}{l}-0.196^{* *} \\
(0.0931)\end{array}$ & $\begin{array}{c}0.179 \\
(0.110)\end{array}$ & $\begin{array}{c}-0.278^{* *} \\
(0.125)\end{array}$ \\
\hline$\triangle \mathrm{TFP}$ & $\begin{array}{c}0.979^{* * *} \\
(0.0521)\end{array}$ & $\begin{array}{c}0.982^{* * *} \\
(0.0565)\end{array}$ & $\begin{array}{l}0.870 * * * \\
(0.0744)\end{array}$ & $\begin{array}{c}0.906^{* * *} \\
(0.126)\end{array}$ & $\begin{array}{l}1.056^{* * *} \\
(0.0954)\end{array}$ \\
\hline$\triangle$ Frontier TFP & $\begin{array}{c}-0.0591^{* *} \\
(0.0295)\end{array}$ & $\begin{array}{c}-0.0809^{* *} \\
(0.0391)\end{array}$ & $\begin{array}{l}-0.0637 \\
(0.0418)\end{array}$ & $\begin{array}{l}-0.0655 \\
(0.0894)\end{array}$ & $\begin{array}{l}-0.0874^{*} \\
(0.0482)\end{array}$ \\
\hline TFP gap (t-1) & $\begin{array}{c}-0.0899 * * * \\
(0.0192)\end{array}$ & $\begin{array}{c}-0.0844^{* * *} * \\
(0.0201)\end{array}$ & $\begin{array}{c}-0.0661^{* * *} \\
(0.0246)\end{array}$ & $\begin{array}{c}-0.178^{* * * *} \\
(0.0540)\end{array}$ & $\begin{array}{r}-0.113^{* * *} \\
(0.0297)\end{array}$ \\
\hline Constant & $\begin{array}{l}-0.0298 \\
(0.0296)\end{array}$ & $\begin{array}{l}-0.0373 \\
(0.0320)\end{array}$ & $\begin{array}{c}-0.0562 \\
(0.0401)\end{array}$ & $\begin{array}{c}0.0574 \\
(0.0592)\end{array}$ & $\begin{array}{l}-0.0345 \\
(0.0454)\end{array}$ \\
\hline $\mathrm{F}$ & $18.98^{* * *}$ & $17.12^{* * *}$ & $12.34^{* * *}$ & $5.479 * * *$ & $12.75^{* * *}$ \\
\hline $\mathrm{R}$ squared & 0.259 & 0.208 & 0.156 & 0.0963 & 0.180 \\
\hline Year dummies $(\mathrm{F})$ & $7.303 * * *$ & $5.175^{* * *}$ & $2.649 * * *$ & $6.375^{* * *}$ & $3.209^{* * *}$ \\
\hline Sector dummies $(F)$ & 1.038 & 0.758 & $2.562^{* * *}$ & 1.401 & 0.848 \\
\hline Country dummies (F) & $4.773^{* * *}$ & $9.982^{* * *}$ & $5.400^{* * *}$ & $2.115^{* *}$ & $9.571^{* * *}$ \\
\hline Ramesey o.v. test (F) & 0.829 & 0.210 & $168.2^{* * *}$ & $9.533^{* * *}$ & $123.9^{* * *}$ \\
\hline $\mathrm{N}$ & 2403 & 2403 & 2403 & 2403 & 2403 \\
\hline
\end{tabular}

The comparison of medium-high technology sectors (table 9) with mediumlow technology sectors (table 10) allows to underline systematic differences in the determinants of emission efficiency growth. Growth at the frontier is more relevant for medium-low than for medium-high technology sectors (with the only exception of NMVOC emissions). Medium-low technology sectors seem to rely on environmentally efficient technologies developed abroad to a greater extent than medium-high technology sectors, for which the development of domestic technologies seems to prevail. Despite that, convergence is faster in medium-high technology sectors due to a stronger positive effect of the emission efficiency gap. On the contrary, productivity gap (in terms of TFP) is more detrimental for emission efficiency growth in medium-high sectors than in medium-low technology sectors, highlighting a stricter link between economic and environmental performance in mediumhigh technology sectors. Finally, evidence for energy prices is more mixed, with emission-specific differences (in magnitude and significance but not in signs) between medium-high and medium-low technology sectors.

To conclude, I report estimates including the lag of emission efficiency growth to account for dynamic adjustments (table 11). Results were obtained by applying the system GMM estimator (Blundell and Bond, 1998). Results were very similar in magnitude and significance to baseline estimates. The coefficient for the lagged dependent variable is significantly negative for $\mathrm{CO} 2, \mathrm{NOx}$ and $\mathrm{SOx}$ and insignificant for NMVOC (positive) and $\mathrm{CO}$ (negative). This means that the dynamic adjustment of emission efficiency growth is not smooth and, on average, occurs by means of accelerations followed by slowdowns. While most covariates show very similar effect to baseline static estimates, a remarkable systematic difference regards 
Table 9: Estimates for medium-high technology sectors

\begin{tabular}{lccccc}
\hline & $\mathrm{CO} 2$ & NOx & NMVOC & SOx & CO \\
\hline$\triangle$ VA/E frontier & 0.0324 & 0.0295 & 0.0416 & $0.118^{* * *}$ & $0.0916^{* *}$ \\
& $(0.0249)$ & $(0.0284)$ & $(0.0309)$ & $(0.0445)$ & $(0.0439)$ \\
VA/E gap (t-1) & $0.0320^{* *}$ & $0.0439^{* * *}$ & 0.00339 & $0.101^{* * *}$ & $0.0413^{* * *}$ \\
& $(0.0148)$ & $(0.0158)$ & $(0.00827)$ & $(0.0216)$ & $(0.0121)$ \\
$\triangle$ energy prices & 0.193 & 0.00279 & $1.388^{* *}$ & 0.413 & $1.548^{* * *}$ \\
& $(0.241)$ & $(0.264)$ & $(0.639)$ & $(0.547)$ & $(0.546)$ \\
energy prices $\times$ & 0.0909 & $0.262^{*}$ & -0.117 & 0.150 & -0.193 \\
VA/E gap (t-1) & $(0.129)$ & $(0.137)$ & $(0.115)$ & $(0.150)$ & $(0.173)$ \\
$\triangle$ TFP & $1.094^{* * *}$ & $1.037^{* * *}$ & $0.879^{* * *}$ & $0.998^{* * *}$ & $1.175^{* * *}$ \\
& $(0.0741)$ & $(0.0830)$ & $(0.118)$ & $(0.159)$ & $(0.159)$ \\
$\triangle$ Frontier TFP & -0.107 & -0.0646 & -0.0769 & -0.237 & -0.190 \\
& $(0.0776)$ & $(0.0885)$ & $(0.0954)$ & $(0.190)$ & $(0.116)$ \\
TFP gap (t-1) & $-0.118^{* * *}$ & $-0.128^{* * *}$ & $-0.0989^{* * *}$ & $-0.296^{* * *}$ & $-0.164^{* * *}$ \\
& $(0.0330)$ & $(0.0326)$ & $(0.0364)$ & $(0.0800)$ & $(0.0451)$ \\
Constant & 0.0211 & 0.0541 & 0.0682 & $0.184^{*}$ & -0.00357 \\
& $(0.0570)$ & $(0.0627)$ & $(0.0604)$ & $(0.0977)$ & $(0.0832)$ \\
\hline F & $14.02^{* * *}$ & $11.62^{* * *}$ & $9.986^{* * *}$ & $5.633^{* * *}$ & $8.226^{* * *}$ \\
R squared & 0.271 & 0.226 & 0.169 & 0.161 & 0.191 \\
Year dummies (F) & $3.064^{* * *}$ & $2.296^{* * *}$ & 1.522 & $7.473^{* * *}$ & $2.448^{* * *}$ \\
Sector dummies (F) & 1.343 & 0.856 & 0.598 & 1.221 & 0.783 \\
Country dummies (F) & $2.728^{* * *}$ & $4.978^{* * *}$ & $4.226^{* * *}$ & $1.661^{*}$ & $4.328^{* * *}$ \\
Ramesey o.v. test (F) & 0.313 & $3.663^{* *}$ & $11.97^{* * *}$ & $15.67^{* * *}$ & $12.54^{* * *}$ \\
$\mathrm{~N}$ & 1091 & 1091 & 1091 & 1091 & 1091 \\
\hline Standard errors in parentheses;* p< $0.1, * * \mathrm{p}<0.05, * * * \mathrm{p}<0.01$ & & \\
\hline
\end{tabular}

the estimated coefficients for the emission efficiency gap that increase substantially for all emissions. Finally, it is worth discussing some specification test on system GMM estimates. The Arellano-Bond test for second order autocorrelation of residuals accepts the null hypothesis of absence of second order autocorrelation for CO2, NMVOC and CO while the null hypothesis cannot be accepted for NOx and SOx. The Hansen test of joint validity of instruments rejects the null hypothesis of weak instruments at the $1 \%$ level of significance for SOx emissions only (the null hypothesis is rejected at the $10 \%$ level of significance for NOx and CO), with both exogenous independent variables (IV) and lags of the dependent variable (GMM) being invalid instruments. Exogenous independent variables are invalid instruments also for NOx emissions. Finally, the difference-in-Hansen test generally shows that instruments were exogenous, the only remarkable exception being exogenous independent variables for $\mathrm{SOx}$ and $\mathrm{CO}$ emissions (the null hypothesis of exogeneity is rejected at the $5 \%$ level of significance).

\section{Concluding remarks}

This paper investigates the dynamics of sectoral emission efficiency in a selection of European countries. International diffusion of more efficient environmental technologies, distance from the technological frontier, energy prices and economic productivity patterns are found to be important drivers of emission efficiency growth in manufacturing sectors.

Results highlight the importance of the diffusion of more environmentally efficient production technologies from leader countries to laggards. However, the channels through which the diffusion occurs are not investigated directly. 
Table 10: Estimates for medium-low technology sectors

\begin{tabular}{|c|c|c|c|c|c|}
\hline & $\mathrm{CO} 2$ & NOx & NMVOC & $\mathrm{SOx}$ & $\mathrm{CO}$ \\
\hline$\triangle \mathrm{VA} / \mathrm{E}$ frontier & $\begin{array}{c}0.0557^{* * *} \\
(0.0212)\end{array}$ & $\begin{array}{c}0.0921^{* * *} \\
(0.0259)\end{array}$ & $\begin{array}{l}0.0491 * \\
(0.0290)\end{array}$ & $\begin{array}{c}0.0822 * * * \\
(0.0282)\end{array}$ & $\begin{array}{c}0.0725^{* *} \\
(0.0302)\end{array}$ \\
\hline $\mathrm{VA} / \mathrm{E} \operatorname{gap}(\mathrm{t}-1)$ & $\begin{array}{l}0.0158 * * * \\
(0.00465)\end{array}$ & $\begin{array}{l}0.0230 * * * \\
(0.00662)\end{array}$ & $\begin{array}{c}0.00757 \\
(0.00604)\end{array}$ & $\begin{array}{c}0.0518^{* * *} \\
(0.0105)\end{array}$ & $\begin{array}{r}0.0240 * * * \\
(0.00811)\end{array}$ \\
\hline$\triangle$ energy prices & $\begin{array}{l}0.0170 \\
(0.170)\end{array}$ & $\begin{array}{c}0.174 \\
(0.246)\end{array}$ & $\begin{array}{l}0.894 \\
(0.601)\end{array}$ & $\begin{array}{l}0.236 \\
(0.490)\end{array}$ & $\begin{array}{c}1.277^{* *} \\
(0.534)\end{array}$ \\
\hline $\begin{array}{l}\triangle \text { energy prices } \times \\
\text { VA } / E \text { gap }(t-1)\end{array}$ & $\begin{array}{c}0.0981 \\
(0.0765)\end{array}$ & $\begin{array}{c}0.124 \\
(0.0959)\end{array}$ & $\begin{array}{l}-0.113 \\
(0.111)\end{array}$ & $\begin{array}{l}0.0784 \\
(0.125)\end{array}$ & $\begin{array}{c}-0.252^{*} \\
(0.131)\end{array}$ \\
\hline$\triangle \mathrm{TFP}$ & $\begin{array}{l}0.867^{* * *} \\
(0.0432)\end{array}$ & $\begin{array}{c}0.951^{* * *} \\
(0.0465)\end{array}$ & $\begin{array}{l}0.902^{* * *} \\
(0.0576)\end{array}$ & $\begin{array}{c}0.766^{* * *} * \\
(0.125)\end{array}$ & $\begin{array}{l}0.881^{* * *} \\
(0.0683)\end{array}$ \\
\hline$\triangle$ Frontier TFP & $\begin{array}{l}-0.0156 \\
(0.0228)\end{array}$ & $\begin{array}{l}-0.0425 \\
(0.0336)\end{array}$ & $\begin{array}{l}-0.0348 \\
(0.0418)\end{array}$ & $\begin{array}{c}0.0562 \\
(0.0842)\end{array}$ & $\begin{array}{l}-0.0102 \\
(0.0464)\end{array}$ \\
\hline TFP gap (t-1) & $\begin{array}{c}-0.0345^{* * *} * \\
(0.0126)\end{array}$ & $\begin{array}{l}-0.0210 \\
(0.0169)\end{array}$ & $\begin{array}{c}-0.00934 \\
(0.0228)\end{array}$ & $\begin{array}{l}-0.0408 \\
(0.0481)\end{array}$ & $\begin{array}{l}-0.00652 \\
(0.0242)\end{array}$ \\
\hline Constant & $\begin{array}{c}-0.0568^{* * *} \\
(0.0208)\end{array}$ & $\begin{array}{c}-0.0628^{* * *} \\
(0.0224)\end{array}$ & $\begin{array}{c}-0.0579^{*} \\
(0.0326)\end{array}$ & $\begin{array}{c}-0.0122 \\
(0.0547)\end{array}$ & $\begin{array}{c}-0.0562 \\
(0.0358)\end{array}$ \\
\hline $\mathrm{F}$ & $22.70^{* * *}$ & $22.68^{* * *}$ & $15.20^{* * *}$ & $5.031 * * *$ & $11.40^{* * *}$ \\
\hline R squared & 0.325 & 0.251 & 0.160 & 0.0856 & 0.169 \\
\hline Year dummies $(\mathrm{F})$ & $8.481^{* * *}$ & $5.514^{* * *}$ & $2.638^{* * *} *$ & $3.409^{* * *}$ & $2.177^{* *}$ \\
\hline Sector dummies $(\mathrm{F})$ & 0.804 & 0.696 & $2.738^{* * *}$ & $4.054^{* * *}$ & $2.492^{* * *}$ \\
\hline Country dummies (F) & $4.320^{* * *}$ & $8.686^{* * *}$ & $3.831^{* * *}$ & $2.053^{* *}$ & $8.523^{* * *}$ \\
\hline Ramesey o.v. test (F) & $2.726^{* *}$ & 0.135 & $83.11^{* * *}$ & $5.441^{* * *}$ & $185.3^{* * *}$ \\
\hline $\mathrm{N}$ & 2024 & 2024 & 2024 & 2024 & 2024 \\
\hline
\end{tabular}

The convergence of emission efficiency towards the frontier is faster for countries and sectors with a greater efficiency gap, probably showing evidence of increasing marginal costs of abatement. Energy prices dynamics has a positive effect on emission efficiency and the effect is decreasing in the emission efficiency gap for CO and NMVOC emission efficiency growth while it is significant only for laggard sectors (and increasing in the emission efficiency gap) for CO2, NOx and SOx emission efficiency growth. Moreover, there is a very robust evidence of complementarity between emission efficiency and economic productivity (here measured with TFP). Finally, the homogeneity of estimates across different types of air emissions is quite surprising, especially in the presence of moderate pairwise correlation between emission efficiency growth rates $^{23}$.

Based on the evidence discussed in this paper concerning the international diffusion of emission efficiency, further research is needed to investigate the way through which sectors in laggard countries take advantage of emission efficiency improvements occurring in the frontier countries. As discussed in the introduction, the diffusion of environmental technologies leading to improvement in emission efficiency may be triggered by a variety of factors. The assessment of the contribution to the diffusion of environmental technologies of these factors is crucial to identifying the optimal policy mix. Finally, it is worth combining patterns of international diffusion with patterns of cross-sectoral diffusion within the same country (Corradini et al, 2011) in a comprehensive framework to obtain a more complete

\footnotetext{
${ }^{23}$ Pairwise correlation between emission efficiency growth rates is greater than 50 percent in just three cases (CO2-NOx, 70 percent; CO-NMVOC, 60.21 percent; NOx-CO, 60.16 percent) and is lower than 20 percent in one case (19.59 percent for NMVOC-SOx).
} 
Table 11: Estimates including lagged dependent variable (system GMM)

\begin{tabular}{|c|c|c|c|c|c|}
\hline & $\mathrm{CO} 2$ & NOx & NMVOC & $\mathrm{SOx}$ & $\mathrm{CO}$ \\
\hline$\triangle \mathrm{VA} / \mathrm{E}(\mathrm{t}-1)$ & $\begin{array}{c}-0.0805^{* * *} \\
(0.0252)\end{array}$ & $\begin{array}{c}-0.177^{* * *} \\
(0.0305)\end{array}$ & $\begin{array}{c}0.0408 \\
(0.0467)\end{array}$ & $\begin{array}{c}-0.184^{* * *} \\
(0.0391)\end{array}$ & $\begin{array}{l}-0.0342 \\
(0.0315)\end{array}$ \\
\hline$\triangle \mathrm{VA} / \mathrm{E}$ frontier & $\begin{array}{c}0.0398^{* *} \\
(0.0168)\end{array}$ & $\begin{array}{c}0.0674^{* * * *} \\
(0.0181)\end{array}$ & $\begin{array}{l}0.0483^{* *} \\
(0.0217)\end{array}$ & $\begin{array}{c}0.106^{* * *} * \\
(0.0290)\end{array}$ & $\begin{array}{c}0.0838^{* * *} * \\
(0.0219)\end{array}$ \\
\hline $\mathrm{VA} / \mathrm{E} \operatorname{gap}(\mathrm{t}-1)$ & $\begin{array}{c}0.0249 * * * \\
(0.00504)\end{array}$ & $\begin{array}{c}0.0403^{* * *} \\
(0.00564)\end{array}$ & $\begin{array}{c}0.0168 * * * \\
(0.00567)\end{array}$ & $\begin{array}{l}0.102 * * * \\
(0.0124)\end{array}$ & $\begin{array}{r}0.0548^{* * *} * \\
(0.00810)\end{array}$ \\
\hline$\triangle$ energy prices & $\begin{array}{l}0.0462 \\
(0.145)\end{array}$ & $\begin{array}{c}0.157 \\
(0.199)\end{array}$ & $\begin{array}{c}1.513^{* * *} \\
(0.512)\end{array}$ & $\begin{array}{c}0.376 \\
(0.392)\end{array}$ & $\begin{array}{c}1.380^{* * *} * \\
(0.396)\end{array}$ \\
\hline $\begin{array}{l}\triangle \text { energy prices } \mathrm{x} \\
\mathrm{VA} / \mathrm{E} \text { gap }(\mathrm{t}-1)\end{array}$ & $\begin{array}{c}0.102 \\
(0.0657)\end{array}$ & $\begin{array}{l}0.173^{* *} \\
(0.0751)\end{array}$ & $\begin{array}{l}-0.167^{*} \\
(0.0904)\end{array}$ & $\begin{array}{c}0.107 \\
(0.0988)\end{array}$ & $\begin{array}{c}-0.234^{* *} \\
(0.100)\end{array}$ \\
\hline$\triangle \mathrm{TFP}$ & $\begin{array}{l}0.940^{* * *} \\
(0.0402)\end{array}$ & $\begin{array}{l}0.971^{* * *} \\
(0.0405)\end{array}$ & $\begin{array}{c}0.911 * * * \\
(0.0602)\end{array}$ & $\begin{array}{l}0.872^{* * *} \\
(0.0992)\end{array}$ & $\begin{array}{l}0.978^{* * *} \\
(0.0726)\end{array}$ \\
\hline$\triangle T F P$ frontier & $\begin{array}{l}-0.0398 \\
(0.0252)\end{array}$ & $\begin{array}{c}-0.0725 * * \\
(0.0361)\end{array}$ & $\begin{array}{r}-0.00378 \\
(0.0427)\end{array}$ & $\begin{array}{l}-0.0375 \\
(0.0793)\end{array}$ & $\begin{array}{l}-0.0576 \\
(0.0506)\end{array}$ \\
\hline TFP gap (t-1) & $\begin{array}{c}-0.0575^{* * *} \\
(0.00823)\end{array}$ & $\begin{array}{c}-0.0747^{* * * *} \\
(0.00965)\end{array}$ & $\begin{array}{c}-0.0380^{* * * *} \\
(0.0101)\end{array}$ & $\begin{array}{c}-0.139^{* * *} \\
(0.0337)\end{array}$ & $\begin{array}{c}-0.0836^{* * * *} \\
(0.0147)\end{array}$ \\
\hline Constant & $\begin{array}{c}0.0672 * * * \\
(0.0136)\end{array}$ & $\begin{array}{c}0.0636 * * * \\
(0.0146)\end{array}$ & $\begin{array}{l}0.0393^{*} \\
(0.0238)\end{array}$ & $\begin{array}{c}-0.121 * * * \\
(0.0425)\end{array}$ & $\begin{array}{l}0.00209 \\
(0.0205)\end{array}$ \\
\hline Chi sq & $1006.5^{* * *}$ & $811.8^{* * *}$ & $342.6^{* * *}$ & $312.3^{* * *}$ & $265.6^{* * *}$ \\
\hline $\operatorname{AR}(1)$ & $-5.431 * * *$ & $-9.102^{* * *}$ & $-5.347^{* * *}$ & $-7.789 * * *$ & $-7.222 * * *$ \\
\hline $\operatorname{AR}(2)$ & 1.300 & $-2.228^{* *}$ & 1.064 & $-2.421^{* *}$ & -0.860 \\
\hline \# instruments & 62 & 55 & 73 & 38 & 38 \\
\hline Sargan test & $232.9 * * *$ & $474.1^{* * *}$ & $479.2^{* * *}$ & $200.6 * * *$ & $174.9^{* * *}$ \\
\hline Hansen test & 43.25 & $54.92 *$ & 65.34 & $39.61^{* * *}$ & $32.37^{*}$ \\
\hline Hansen test (GMM) & 38.84 & $44.03^{* *}$ & 50.65 & $22.81^{* * *}$ & $14.93^{*}$ \\
\hline Hansen test (diff - GMM) & 4.41 & 10.89 & 14.69 & $16.8^{*}$ & $17.44^{*}$ \\
\hline Hansen test (IV) & 27.94 & $37.37^{* * *}$ & 45.47 & $11.13^{* * *}$ & 3.93 \\
\hline Hansen test (diff - IV) & 15.3 & 17.55 & 19.87 & $28.48^{* *}$ & $28.44^{* *}$ \\
\hline $\mathrm{N}$ & 2848 & 2848 & 2848 & 2848 & 2848 \\
\hline
\end{tabular}

representation of the diffusion of emission efficient technologies.

\section{A Air emission features}

Emissions differ substantially as regards the 'external cost' they produce. Carbon dioxide emissions have no direct effect on health and on local communities whereas they contribute to the greenhouse effect and global climate change. On the contrary, other emissions (NOx, SOx, NMVOC and CO) have serious effects on health and damage the environment at the local level through acidification (NOx and SOx), ozone depletion (NOx), eutrophication (NOx) and tropospheric ozone formation (CO and NOx).

These difference resulted in different timing and characteristics of national or supra-national regulations. Pollutant emissions have been regulated at the European level since the mid 80s through a series of Directives which have eased the harmonization of national policies. Among others, consider the following directives aimed at regulating pollution. The Sulphur Dioxide Air Pollution Directive, approved in 1980 (1980/779/EEC), aimed at reducing SOx emissions while the Nitrogen Dioxide Air Pollution Directive approved in 1985 (1985/203/EEC) focused on the reduction of NOx emissions. They were replaced by the First Daughter Directive 'Sulphur Dioxide, Nitrogen Dioxide and Oxides of Nitrogen, Particulate Matter and Lead in Ambient Air' in 1999 (99/30/EC) broadening the scope of pollutant reductions to SOx and other local pollutants. The Fuel Quality Directive 
introduced in 1998 (98/70/EC), revised in 2003 (2003/17/EC) and in 2009 (2009/30/EC), sets specific requirements for the quality of fuels in order to reduce emissions of pollutant substances. The NEC (National Emission Ceilings) Directive (2001/81/EC), approved by the European Commission in 2001, sets legally binding limits to national emissions of NOx, SO2, NMVOC and ammonia. Finally, a broader programme to consider air pollution emissions in a comprehensive way was launched by the European Commission in 2005 (Clean Air For Europe programme CAFE).

On the contrary, regulatory efforts explicitly aimed at reducing carbon dioxide emissions were less effective. No relevant policy was introduced before the approval of the Kyoto Protocol (1997) and, even after the protocol started being legally binding (2001), no real action was taken before the introduction of the Emission Trading Scheme (in its pilot phase) in 2005 and the '20-20-20' strategy proposed in 2007. 


\section{References}

Blundell R, Bond S (1998) Initial conditions and moment restrictions in dynamic panel data models. Journal of Econometrics 87(1):115-143

Carrión-Flores CE, Innes R (2010) Environmental innovation and environmental performance. Journal of Environmental Economics and Management 59(1):27-42

Cole MA, Elliott RJ, Shimamoto K (2005) Industrial characteristics, environmental regulations and air pollution: an analysis of the UK manufacturing sector. Journal of Environmental Economics and Management $50(1): 121-143$

Corradini M, Costantini V, Mancinelli S, Mazzanti M (2011) Environmental and innovation performance in a dynamic impure public good framework. Departmental Working Papers of Economics - University 'Roma Tre' No. 0141, Department of Economics - University Roma Tre

Costantini V, Mazzanti M (2010) On the green side of trade competitiveness? environmental policies and innovation in the EU. Working Papers 2010.94, Fondazione Eni Enrico Mattei

Jaffe AB, Newell RG, Stavins RN (2005) A tale of two market failures: Technology and environmental policy. Ecological Economics 54(2-3):164174

Lanjouw JO, Mody A (1996) Innovation and the international diffusion of environmentally responsive technology. Research Policy 25(4):549-571

Lovely M, Popp D (2011) Trade, technology, and the environment: Does access to technology promote environmental regulation? Journal of Environmental Economics and Management 61(1):16-35

Marin G, Mazzanti M (in press) The evolution of environmental and labor productivity dynamics - sector analyses and decoupling/recoupling trends on a 1990-2007 Italian NAMEA. Journal of Evolutionary Economics URL http://dx.doi.org/10.1007/s00191-010-0199-8

Mazzanti M, Musolesi A (2010) Carbon abatement leaders and laggards non parametric analyses of policy oriented Kuznets curves. Working Papers 2010.149, Fondazione Eni Enrico Mattei

Mazzanti M, Zoboli R (2009) Environmental efficiency and labour productivity: Trade-off or joint dynamics? a theoretical investigation and empirical evidence from Italy using NAMEA. Ecological Economics 68(4):1182-1194 
Moomaw WR, Unruh GC (1997) Are environmental Kuznets curves misleading us? the case of $\mathrm{CO} 2$ emissions. Environment and Development Economics 2(04):451-463

Newell RG, Jaffe AB, Stavins RN (1999) The induced innovation hypothesis and energy-saving technological change. The Quarterly Journal of Economics 114(3):941-975

Nicoletti G, Scarpetta S (2003) Regulation, productivity and growth: OECD evidence. Economic Policy 18(36):9-72

Popp D (2002) Induced innovation and energy prices. American Economic Review 92(1):160-180

Popp D (2006) International innovation and diffusion of air pollution control technologies: the effects of NOx and SO2 regulation in the US, Japan, and Germany. Journal of Environmental Economics and Management $51(1): 46-71$

Popp D, Newell RG, Jaffe AB (2009) Energy, the environment, and technological change. NBER Working Papers 14832, National Bureau of Economic Research, Inc

Porter ME, van der Linde C (1995) Toward a new conception of the environment-competitiveness relationship. Journal of Economic Perspectives $9(4): 97-118$

Scarpetta S, Tressel T (2002) Productivity and convergence in a panel of OECD industries: Do regulations and institutions matter? OECD Economics Department Working Papers 342, OECD Publishing 


\section{Institution Markets \\ IMT}

INSTITUTE FOR ADVANCED STUDIES LUCCA

2012 ( ) IMT Institute for Advanced Studies, Lucca Piazza San ponziano 6, 5100 Lucca, Italy. www.imtlucca.it 